\title{
French-Canadian version of the Chronic Respiratory and St George's Respiratory questionnaires: An assessment of their psychometric properties in patients with chronic obstructive pulmonary disease
}

\author{
Jean Bourbeau MD¹, Francois Maltais $M D^{2}$, Michel Rouleau $M^{3}{ }^{3}$, Chantal Guímont $M^{3}$
}

\begin{abstract}
J Bourbeau, F Maltais, M Rouleau, C Guímont. FrenchCanadian version of the Chronic Respiratory and St George's Respiratory questionnaires: An assessment of their psychometric properties in patients with chronic obstructive pulmonary disease. Can Respir J 2004;11(7):480-486.
\end{abstract}

BACKGROUND: French versions of the Chronic Respiratory Questionnaire (CRQ) and the St George's Respiratory Questionnaire (SGRQ) have largely been used in Canada, although the process by which they were translated remains unknown and the psychometric properties of these translated versions have not been assessed in a properly designed study.

OBJECTIVE: To translate and evaluate the psychometric properties of the French-Canadian versions of the CRQ and the SGRQ.

METHODS: The questionnaires were translated according to standardized guidelines for cross-cultural adaptation. Measurements were made at baseline and again after two weeks in 27 chronic obstructive pulomonary disease (COPD) patients known to have stable disease. Measurements were also taken pre- and post-treatment in patients with acute exacerbation of COPD (33 patients) or in pulmonary rehabilitation (32 patients).

RESULTS: The CRQ showed high test-retest reliability (the majority above 0.70 ), although it was slightly lower for the dyspnea dimension (0.58 to 0.65$)$. The SGRQ also showed high test-retest reliability (above 0.80 ), although it was lower for the symptoms dimension $(0.54$ to 0.58$)$. The internal consistency reliability coefficients ranged from 0.73 to 0.90 for the CRQ and above 0.80 for the SGRQ, except for the symptoms dimension. The Pearson's correlation coefficients were low (less than 0.30) between most of the translated questionnaire dimension scores and forced expiratory volume in $1 \mathrm{~s}, 6$ min walking test and dyspnea measures. The correlation was generally high (greater than $0.50)$ between the two questionnaires and the 36-item short form health survey, and for those domains that measured the same construct. The changes in the total and subscale scores of the CRQ and the SGRQ (except for the symptoms domain) were all largely above the variability of the score in the stable disease group.

CONCLUSION: The present study confirms that the FrenchCanadian translated versions of the CRQ and the SGRQ perform well with respect to their psychometric properties. They are both suitable for their intended purpose, ie, to detect change in health status in patients with COPD when assessing if a treatment is beneficial. However, the symptoms domain of the SGRQ cannot be used to assess acute change with respect to a given therapy.

Key Words: COPD; Chronic Respiratory Questionnaire; Psychometric properties; Quality of life; Questionnaire; St George's Respiratory Questionnaire

\author{
Version québécoise du «Chronic Respiratory \\ Questionnaire » et du «St George Respiratory \\ Questionnaire » : Évaluation des propriétés \\ psychométriques chez des patients atteints d'une \\ bronchopneumopathie chronique obstructive
}

CONTEXTE : Les versions québécoises du « Chronic Respiratory Questionnaire » (CRQ) et du "St George Respiratory Questionnaire » (SGRQ) sont très utilisées au Canada, même si on ne connaît pas le processus de traduction appliqué et même si les propriétés psychométriques de ces versions traduites n'ont pas fait l'objet d'évaluation dans une étude appropriée.

OBJECTIF : Traduire et évaluer les propriétés psychométriques des versions québécoises du CRQ et du SGRQ.

MÉTHODE : Les questionnaires ont été traduits suivant des lignes directrices uniformisées en vue d'une adaptation interculturelle. Des mesures ont été prises au départ, puis deux semaines plus tard, chez 27 patients atteints d'une bronchopneumopathie chronique obstructive (BPCO) stable. Des mesures ont également été prises chez 33 patients présentant une exacerbation de $\mathrm{BPCO}$, avant et après le traitement, ainsi que chez 32 autres patients suivis en réadaptation pulmonaire.

RÉSULTATS : Le CRQ a montré une bonne fiabilité de test-retest (audessus de 0,70 dans la plupart des cas), même si celle-ci était légèrement inférieure $(0,58-0,65)$ à l'égard de la dyspnée. Le SGRQ a aussi montré une bonne fiabilité de test-retest (au-dessus de 0,80), même si celle-ci était légèrement inférieure $(0,54-0,58)$ à l'égard des symptômes. Les coefficients de cohérence interne variaient entre 0,73 et 0,90 pour le CRQ et ils se tenaient au-dessus de 0,80 pour le $S G R Q$, sauf en ce qui concerne les symptômes. Les coefficients de corrélation de Bravais-Pearson étaient faibles (inférieurs à 0,30 ) entre la plupart des résultats des différents aspects dans les questionnaires traduits et le volume expiratoire maximal par seconde, l'épreuve de marche de 6 minutes et les mesures de la dyspnée. Par contre, la corrélation était généralement forte (supérieure à 0,50) entre les deux questionnaires et le questionnaire abrégé en 36 points, utilisé pour l'enquête sur la santé ainsi qu'entre les domaines qui mesuraient le même construct. Les écarts entre les résultats totaux et les résultats partiels au CRQ et au SGRQ (à l'exception de la partie sur les symptômes) étaient bien au-dessus de la variabilité du score enregistré dans le groupe atteint d'une maladie stable.

CONCLUSION : La présente étude confirme que les versions françaises du CRQ et du SGRQ sont bien adaptées au contexte québécois pour ce qui est des propriétés psychométriques. Les deux traductions conviennent aux fins prévues, c'est-à-dire qu'elles décèlent des changements dans l'état de santé chez les patients atteints d'une BPCO pour évaluer l'efficacité d'un traitement. Par contre, la partie portant sur les symptômes dans le SGRQ ne peut être utilisée pour évaluer des changements rapides par rapport à un traitement donné.

${ }^{1}$ Respiratory Epidemiology and Clinical Research Unit, Montreal Chest Institute of the Royal Victoria Hospital, McGill University Health Centre, Montreal; ${ }^{2}$ Hôpital Laval, Institut universitaire de cardiologie et de pneumologie, Université Laval, Sainte-Foy; ${ }^{3}$ Hôpital du St-Sacrement, Centre Universitaire affilié de l'Université Laval, Quebec

Correspondence and reprints: Dr Jean Bourbeau, Respiratory Epidemiology and Clinical Research Unit, Montreal Chest Institute of the Royal Victoria Hospital, McGill University Health Centre, 3650 St Urbain, Room K1.32, Montreal, Quebec H2X 2P4. Telephone 514-934-1934 ext 32185, fax 514-843-2083, e-mail jean.bourbeau@mcgill.ca 
C hronic obstructive pulmonary disease (COPD) may contribute to considerable limitations in various aspects of a patient's daily life $(1,2)$. Spirometry results have been used for the past few decades to assess disease severity or evaluate treatment benefits in COPD patients; however, measurements of conventional lung function are not closely related to disability $(3,4)$. Measurements of the symptomatic state using existing questionnaires are often directed towards physical symptoms, such as dyspnea, as in the Medical Research Council questionnaire (5). It is well accepted that the goal of therapy in COPD should not be only to improve the physiological and functional state, but also to minimize the effects of the disease on the patients' quality of life (6).

While a physician's impression of a patient may be adequate to guide individual therapy, it is not readily communicated to others in the context of collecting and analyzing data from a group of patients. Quality of life instruments have been developed to assess overall measures of health or disease-specific measures. The two most commonly used instruments in health-related quality of life specific to COPD are the Chronic Respiratory Questionnaire (CRQ) and St George's Respiratory Questionnaire (SGRQ).

The CRQ was developed in English by Guyatt et al in 1987 (7) to provide a comprehensive measure of health suitable for detecting changes following therapy in patients with COPD. The SGRQ was developed in 1992 by Jones et al (8) to measure impaired health and perceived well-being in patients with airway disease, and to meet the need for a sensitive measure of health. These two questionnaires have been used worldwide in many studies, as well as in various clinical settings. A FrenchCanadian version of the CRQ and the SGRQ has yet to be adapted and validated in a properly designed study. The purpose of the present study was to adapt a French-Canadian version of the CRQ and SGRQ and assess the performance of the adapted French-Canadian versions of the questionnaires with respect to their psychometric properties.

We hypothesized that the translated CRQ and SGRQ total and subscale scores would have a higher correlation with other questionnaire (36-item short form health survey [SF-36]) measures of similar constructs than with traditional measurements such as lung function, standardized walking tests and exertional dyspnea. Furthermore, we also hypothesized that the scores would demonstrate not only improvement in health resulting from a therapeutic intervention, but that the improvement would be sufficiently large relative to the variability shown in patients with stable disease.

\section{METHODS}

The study was conducted among French-Canadian COPD patients from three university hospitals in the province of Quebec. The study protocol was approved by the research ethics board of each of the hospitals. The study included two phases: Canadian French-language cross-cultural adaptation of the CRQ and SGRQ, and evaluation of the psychometric properties of the French-Canadian language version of the CRQ and SGRQ.

French-Canadian language cross-cultural adaptation of the CRQ and SGRQ

The purpose of the translation was not to provide a literal conversion of the questionnaire, but to convey the spirit of the questionnaire items in a different language and culture. Standardized guidelines for cross-cultural adaptation of the CRQ and the SGRQ were applied as proposed by Guillemin et al (9). Adaptation procedures included the following steps: first, translation from English to French; second, back-translation; third, committee review and final version; and finally, pretesting. Translations were undertaken by two independent translators who were aware of the intent underlying the material and included one health professional and one professional translator without any expertise in the disease. The translators translated into their mother tongue. Backtranslation into the source language was done by a professional translator not aware of the intent and concept underlying the material. A committee was formed to produce a final version. The committee consisted of three bilingual individuals: two experts in the disease and one nonexpert. Discrepancies were resolved by consensus, and when needed, contacts were made with the author of the original questionnaire. Finally, the French-Canadian questionnaire was administered to a small group of patients to detect any errors and determine whether the different items of the questionnaire had been understood correctly.

\section{Psychometric properties of the French-Canadian language version of CRQ and SGRQ}

The measurement properties of the French-Canadian language CRQ and SGRQ, with respect to reliability, validity and responsiveness, were examined as part of two different clinical settings. The first clinical setting, a stable disease group, represented COPD patients whose disease was expected to remain stable over two weeks. Patients with confirmed stable COPD were evaluated at baseline and again after two weeks. The stable disease group allowed the assessment of the reproducibility of the questionnaire.

The second clinical setting, a disease improvement group, represented COPD patients whose health status was expected to improve while being treated with a known, beneficial intervention. Patients were evaluated before and after treatment completion. This clinical setting included two subgroups of patients: patients treated for an exacerbation of COPD, with assessments within $24 \mathrm{~h}$ of the diagnosis of the exacerbation and at four weeks after treatment initiation, and patients taking part in an eight- to 12-week respiratory rehabilitation program with assessments before initiating the program and immediately after completion of the exercise training program. The disease improvement group allowed the assessment of the validity of the questionnaire by comparing the SGRQ score changes with other instrument measures known to be associated with disease improvement, such as forced expiratory volume in $1 \mathrm{~s}\left(\mathrm{FEV}_{1}\right), 6$ min walking test (6MWT), $\mathrm{O}_{2}$ cost diagram (OCD) and SF-36. Responsiveness to change was assessed using the disease improvement group, ie, patients whose condition was expected to improve while they were on treatment, and comparing these changes with those of patients in the stable disease group.

\section{Patient selection}

Patients with COPD were selected from three university hospitals: Laval Hospital (Sainte-Foy), Montreal Chest Institute of the Royal Victoria Hospital (Montreal) and St Sacrement Hospital (Quebec City). Enrollment was done on a sequential basis and occurred through the outpatient clinic, emergency department and hospitalbased rehabilitation program. An explanation of the project was provided and written consent was signed by all participants. 
To be eligible for the study, all patients had to meet the following criteria: COPD diagnosis (10) as the primary functional limiting factor; $\mathrm{FEV}_{1}$ less than $70 \%$ predicted normal (11) and $\mathrm{FEV}_{1} /$ forced vital capacity (FVC) less than 0.70 ; no clinical or laboratory evidence of another major organ disease; no other disease that could alter health status in the short term; and either of the two clinical settings: stable disease or disease improvement.

The stable disease clinical setting was defined as the patient having stable respiratory symptoms, unchanged medication and an $\mathrm{FEV}_{1}$ variation of less than $15 \%$ and $150 \mathrm{~mL}$, assessed at baseline and after two weeks.

The disease improvement clinical setting was defined according to the two following clinical situations: patients having an acute exacerbation, ie, worsening of their respiratory symptoms (dyspnea, sputum production or change in the colour of sputum) associated with a reduction of $\mathrm{FEV}_{1}$ of at least $15 \%$ and $150 \mathrm{~mL}$ from baseline, and requiring additional therapy with prednisone and/or an antibiotic; or patients taking part in an outpatient, hospital-based pulmonary rehabilitation program.

\section{Outcome measures}

Face-to-face interviews were conducted in each participating centre, using the CRQ, SGRQ and SF-36 in random order. Interviewers in each participating centre had previous experience in questionnaire administration specific to asthmatic and COPD patients. Questionnaire administration was standardized between sites, and a procedure guide was provided to each interviewer.

The CRQ is composed of four dimensions: dyspnea, which is rated on a set of activities generated by each patient individually, and, therefore, not standardized; fatigue, a symptom that has been reported as important in COPD (12); emotional function; and mastery: the latter two are important domains related to COPD (12). The questionnaire refers to the past two weeks for the four dimensions. Subjects were informed of their previous responses when answering the questionnaire for the second time. The scores range from 5 to 35 for dyspnea, 4 to 28 for fatigue, 7 to 49 for emotional function and 4 to 28 for mastery. A high score indicates better function, and a decrease in the score indicates a deterioration in function (13).

The SGRQ (8) is composed of three dimensions: specific respiratory symptoms; activity, a measure of the activities that cause or are limited by breathlessness; and impact, a measure of the overall disturbance of daily life, social function and well-being. The questions refer to the past year for the respiratory symptom domain, and to a recent period denoted by "these days" for activity and impact dimensions. The scoring range is 0 to 100 . A high score indicates poor health and a decrease in the score indicates an improvement in quality of life.

The SF-36 (14) is composed of 36 questions covering nine domains: physical and social functioning, physical and social role, mental health, pain index, vitality, general health perceptions and health transition. The questions in each of the health scales refer to the present health status. For all measures of health components, the scores are transformed linearly to scales of 0 to 100 . A high score indicates a better health state, and a decrease in the score indicates deterioration in quality of life. The SF-36 examines the past year for disease transition. The questionnaire originated in English and has been validated; it was adequately translated and the translated version was also validated $(15,16)$.
According to the American Thoracic Society standardized guidelines (17), pulmonary function tests were assessed with a calibrated rolling seal spirometer. FEV 1 and FVC were done before and after bronchodilators. The 6MWT was used as a field test to assess the patients' exercise capacity. Patients were instructed to walk from end to end over a $30 \mathrm{~m}$ distance, to cover as much ground as possible in the allotted time (18). The test was performed twice and the best performance was used for analysis. Exertional dyspnea was measured with a visual analogue scale, $100 \mathrm{~mm}$ in length; the verbal anchor at the bottom was "no breathlessness" and "greatest breathlessness" was at the top $(19,20)$. The OCD (3) was used to assess dyspnea with daily activities. The OCD is a $100 \mathrm{~mm}$ line on which 13 activities are indicated, with their position proportional to the $\mathrm{O}_{2}$ cost or requirement. The score recorded is the distance (in $\mathrm{mm}$ ) from the bottom of the line. The OCD has shown evidence of validity (21) and sensitivity to change (22).

\section{Statistical analysis}

The psychometric properties of the CRQ and SGRQ were assessed with respect to reliability, validity and responsiveness. Reliability refers to the stability of the measurement across items and over time (reproducibility). Reproducibility (test-retest reliability) was estimated by administering the questionnaire repeatedly over a short time period of two weeks to patients from the stable disease group. Pearson's correlation coefficient was calculated to assess the degree of association between the test and retest scores. However, this test does not indicate the direction of the association. For example, if everyone consistently scored higher on the retest, the correlation coefficient would be highly positive. To overcome this, the intraclass correlation with the $95 \%$ CI was calculated. The intraclass correlation evaluates not only the degree of association but also the degree of agreement between different quantitative observations, which is a special case of association. Finally, the internal consistency of the instrument, the extent to which items in a dimension are correlated with each other, was assessed using Cronbach's coefficient.

The validity of a questionnaire is the extent to which the measure accurately represents a patient's health status or quality of life, but it is conceptually difficult to demonstrate because there is no true standard. 'Construct validity' has been used to demonstrate the validity in an indirect fashion. This approach of validating a questionnaire consists of demonstrating that its results match those of other instrument measures known to change after a given intervention. Using Pearson's correlation coefficient, the CRQ and the SGRQ scores were compared with another health-related quality of life questionnaire, the SF-36, and other measures $\left(\mathrm{FEV}_{1}, 6 \mathrm{MWT}\right.$, and dyspnea using the OCD and after exertion) known to change when a patient's disease improves. It was expected that a low (less than 0.30) to moderate ( 0.30 to 0.50$)$ correlation would be found between the diseasespecific questionnaires under study and $\mathrm{FEV}_{1}, 6 \mathrm{MWT}$ and dyspnea measures. The correlation between the disease-specific questionnaires and the SF-36 was expected to be higher (greater than 0.50) than those with $\mathrm{FEV}_{1}, 6 \mathrm{MWT}$ and dyspnea measures.

The responsiveness to change and the extent to which scores change with a given change in health-related quality of life were also assessed. The ability of the questionnaire to detect change and improvement over time was used as an index of responsiveness by 
comparing the change in patients from the disease improvement group with change from patients in the stable disease group (23). The questionnaire was considered to be responsive if the scores demonstrated not only improvement in health-related quality of life when the other measures predict it, but also sufficiently large improvement relative to the variability shown in patients in the stable disease clinical setting.

\section{RESULTS}

Twenty-seven COPD patients of the stable disease group were confirmed to have stable disease based on measures taken two weeks apart, while 65 COPD patients constituted the disease improvement group. The disease improvement group was divided into two subgroups: 33 patients followed from the onset of an exacerbation to its resolution and 32 patients in an outpatient hospital-based, supervised pulmonary rehabilitation program.

Patient characteristics are presented in Table 1. Patients' age, sex and $\mathrm{FEV}_{1}$ reversibility as predicted normal value were similar among the studied groups. The prevalence of smoking was lower in the pulmonary rehabilitation group than in the two other groups. As expected, patients with an exacerbation of COPD presented with a lower $\mathrm{FEV}_{1}$ and $\mathrm{FEV}_{1} / \mathrm{FVC}$ ratio than the two other groups. $\mathrm{FEV}_{1}$ was similar between patients in the rehabilitation program and patients in the stable disease group. Dyspnea was more severe in patients with an acute exacerbation or taking part in a rehabilitation program than in patients in the stable disease group.

Test-retest reliability and internal consistency are presented in Table 2. The CRQ showed high test-retest reliability using the Pearson correlation and the intraclass correlation coefficients (the majority were above 0.70), although they were slightly lower for the dyspnea dimension (0.58 to 0.65 ). The SGRQ also showed high test-retest reliability (above 0.80), although it was lower for the symptoms dimension $(0.54$ to 0.58). The coefficient of variation was $12 \%$ or lower for both questionnaires. The internal consistency reliability coefficients (Cronbach's coefficients) ranged from 0.73 to 0.90 for the CRQ and above 0.80 for the SGRQ, except for the symptoms dimension.

Table 3 shows the correlation between the study questionnaires with various outcome measures. Pearson's correlation coefficients were low (less than 0.30) between most of the translated questionnaires (CRQ and SGRQ) dimension scores and $\mathrm{FEV}_{1}, 6 \mathrm{MWT}$, dyspnea after exertion and OCD. Correlation was moderate $(0.30$ to 0.50$)$ between the fatigue dimension of the CRQ and dyspnea measured after exertion and OCD. Correlation was also moderate between the SGRQ and OCD (except for the symptoms dimension), and between the activity dimension and the 6MWT. Correlation was generally high (greater than 0.50 ) between the two study questionnaires and the SF-36. Dyspnea subscale scores of the CRQ correlated best with physical functioning and general health perception dimensions of the SF-36; fatigue with physical functioning, role functioning/emotion and role functioning/physical; emotion and mastery with role functioning/emotion. The activity subscale of the SGRQ had a high correlation with physical functioning and role functioning/physical, and the impact subscale had a high correlation
TABLE 1

Baseline characteristics of the chronic obstructive pulmonary disease (COPD) study population

\begin{tabular}{|c|c|c|c|}
\hline \multirow[b]{2}{*}{ Characteristic } & \multirow[b]{2}{*}{$\begin{array}{l}\text { Stable disease } \\
\text { group }(n=27)\end{array}$} & \multicolumn{2}{|c|}{ Disease improvement group } \\
\hline & & $\begin{array}{c}\text { Acute } \\
\text { exacerbation } \\
(n=33)\end{array}$ & $\begin{array}{c}\text { Rehabilitation } \\
\text { program } \\
(n=32)\end{array}$ \\
\hline Age (years [SD]) & $67.7(8.6)$ & $68.2(9.4)$ & $68.3(8.9)$ \\
\hline Sex (\% male $)$ & 78 & 67 & 70 \\
\hline \multicolumn{4}{|l|}{$\mathrm{FEV}_{1}(\mathrm{~L}[\mathrm{SD}])$} \\
\hline Pre-BD & $0.92(0.26)$ & $0.69(0.29)$ & $0.90(0.35)$ \\
\hline Post-BD & $1.08(0.29)$ & $0.76(0.33)$ & $1.04(0.41)$ \\
\hline $\begin{array}{l}\text { Post }- \text { Pre/ } \\
\text { predicted FEV } 1\end{array}$ & $0.06(0.04)$ & $0.04(0.05)$ & $0.05(0.04)$ \\
\hline $\mathrm{FEV}_{1} / \mathrm{FVC}$ & $0.45(0.11)$ & $0.41(0.10)$ & $0.46(0.11)$ \\
\hline Smoking (pack-years) & $53.6(30.01)$ & $54.7(39.0)$ & $48.1(22.3)$ \\
\hline $\begin{array}{l}\text { Dyspnea } \geq 4 \text { of } 5 \\
\text { (ATS scale [\%]) }\end{array}$ & 52 & 88 & 84 \\
\hline Chronic bronchitis (\%) & 48 & 41 & 31 \\
\hline
\end{tabular}

ATS American Thoracic Society; BD Bronchodilator; FEV ${ }_{1}$ Forced expiratory volume in $1 \mathrm{~s}$; FVC Forced vital capacity

with physical functioning, role functioning/physical and general health perception.

Table 4 shows the correlation between changes of the study questionnaire scores following treatment with the change of other outcome measures. No significant correlation could be demonstrated between the change of the CRQ scores and any of the other physiological or clinical outcome measures. However, the correlation was moderate between the total score and the subscale score changes of the fatigue and emotion dimensions of the CRQ with the total score of the SF-36. The dyspnea subscale score change correlated best with physical functioning, and fatigue correlated best with role functioning/emotion and role functioning/physical. For the SGRQ, a significant correlation could only be demonstrated between total score and OCD (0.34), and the SGRQ activity subscale and 6MWT (0.30). The correlation was moderate $(0.30$ to 0.50 ) when comparing the change in the SGRQ total scores with the SF-36 total score, as well as with the physical functioning and role functioning/physical subscales. The activity subscale of the SGRQ had a moderate correlation with role functioning/physical, and the impact subscale had a moderate correlation with physical functioning and role functioning/physical subscales.

Table 5 shows the responsiveness to the French-Canadian language version following treatment when improvement was expected. The changes in the total and subscale scores of the CRQ and the SGRQ (except for the symptoms domain) were all largely above the variability of the score in the stable disease group.

\section{DISCUSSION}

Our study demonstrated excellent test-retest reliability (stability over time) and internal consistency (stability across items of a same domain) for the new French-Canadian version of the CRQ and the SGRQ. The questionnaire reliability compares favourably with those of previous studies of the original 
TABLE 2

Reliability of of the French-Canadian translated version of the Chronic Respiratory Questionnaire (CRQ) and the St George's Respiratory Questionnaire (SGRQ)

\begin{tabular}{|c|c|c|c|c|c|c|c|c|c|}
\hline \multirow[b]{2}{*}{ Test } & \multicolumn{5}{|c|}{ CRQ (n=27) } & \multicolumn{4}{|c|}{ SGRQ (n=27) } \\
\hline & Total & Dyspnea & Fatigue & Emotion & Mastery & Total & Symptoms & Activity & Impact \\
\hline \multicolumn{10}{|l|}{ Test-retest } \\
\hline Intraclass correlation & $0.78^{\star}$ & $0.58^{*}$ & $0.70^{*}$ & $0.74^{*}$ & $0.80^{*}$ & $0.89^{*}$ & $0.54^{*}$ & $0.86^{*}$ & $0.89^{*}$ \\
\hline coefficient $(95 \% \mathrm{Cl})$ & $(0.63-0.87)$ & $(0.34-0.75)$ & $(0.43-0.78)$ & $(0.58-0.85)$ & $(0.66-0.88)$ & $(0.81-0.94)$ & $(0.30-0.72)$ & $(0.76-0.92)$ & $(0.81-0.94)$ \\
\hline Pearson's correlation & $0.87^{*}$ & $0.65^{*}$ & $0.75^{*}$ & $0.78^{*}$ & $0.81^{*}$ & $0.90^{*}$ & $0.56^{*}$ & $0.87^{*}$ & $0.90^{*}$ \\
\hline Coefficient of variation, \% & 8 & 12 & 12 & 4 & 4 & 5.5 & 9.2 & 1.8 & 8.2 \\
\hline \multicolumn{10}{|l|}{ Internal consistency } \\
\hline \multicolumn{10}{|l|}{ Cronbach's alpha } \\
\hline Baseline & 0.89 & 0.74 & 0.79 & 0.77 & 0.73 & 0.90 & 0.54 & 0.83 & 0.87 \\
\hline Two weeks later & 0.90 & 0.85 & 0.86 & 0.73 & 0.76 & 0.85 & 0.53 & 0.82 & 0.87 \\
\hline
\end{tabular}

*Statistically significant $(P<0.05)$

TABLE 3

Validity of the French-Canadian translated version of the Chronic Respiratory Questionnaire (CRQ) and the St George's Respiratory Questionnaire (SGRQ): Pearson's correlation coefficients among the study questionnaire scores and other outcome measures

\begin{tabular}{|c|c|c|c|c|c|c|c|c|c|}
\hline \multirow[b]{2}{*}{ Test } & \multicolumn{5}{|c|}{$C R Q(n=65)$} & \multicolumn{4}{|c|}{ SGRQ (n=65) } \\
\hline & Total & Dyspnea & Fatigue & Emotion & Mastery & Total & Symptoms & Activity & Impact \\
\hline $\mathrm{FEV}_{1}$ & 0.15 & -0.01 & 0.27 & 0.10 & 0.09 & $-0.28^{*}$ & -0.07 & -0.24 & $-0.28^{*}$ \\
\hline Six-minute walking test & 0.35 & 0.14 & 0.05 & 0.18 & 0.10 & $-0.29^{*}$ & 0.04 & $-0.40^{*}$ & -0.24 \\
\hline Dyspnea after exertion & -0.23 & 0.06 & $-0.32^{*}$ & -0.17 & -0.26 & 0.22 & 0.20 & 0.12 & 0.21 \\
\hline $\mathrm{O}_{2}$ cost diagram & 0.22 & 0.14 & $0.37^{*}$ & 0.24 & 0.09 & $-0.39^{*}$ & -0.03 & $-0.50^{*}$ & $-0.32 *$ \\
\hline \multicolumn{10}{|l|}{ SF-36 } \\
\hline Total score & $0.76^{*}$ & $0.51^{*}$ & $0.67^{*}$ & $0.72^{*}$ & $0.49^{*}$ & $-0.76^{*}$ & $-0.41^{*}$ & $-0.67^{*}$ & $-0.69^{*}$ \\
\hline Physical functioning & $0.38^{*}$ & $0.43^{*}$ & $0.38^{*}$ & $0.30^{*}$ & 0.08 & $-0.62^{*}$ & $-0.26^{*}$ & $-0.61^{*}$ & $-0.55^{\star}$ \\
\hline Role functioning/emotion & $0.62^{*}$ & $0.37^{*}$ & $0.45^{\star}$ & $0.64^{*}$ & $0.46^{*}$ & $-0.51^{*}$ & -0.19 & $-0.49^{*}$ & $-0.48^{*}$ \\
\hline Role functioning/physical & $0.38^{*}$ & 0.25 & $0.55^{\star}$ & $0.32^{*}$ & 0.22 & $-0.64^{*}$ & $-0.36^{\star}$ & $-0.69^{*}$ & $-0.52^{*}$ \\
\hline General health perception & 0.43 & $0.44^{*}$ & $0.13^{*}$ & $0.36 *$ & 0.14 & $-0.52^{*}$ & $-0.38^{*}$ & $-0.34^{*}$ & $-0.52^{*}$ \\
\hline
\end{tabular}

*Statistically significant $(P<0.05)$. FEV ${ }_{1}$ Forced expiratory volume in $1 \mathrm{~s}$; SF-36 36-item short form health survey

English CRQ (7,24) and SGRQ (8,25). However, the dimension symptoms subscale of the SGRQ did not do as well. All of the necessary precautions were taken to ensure that patients were clinically stable before considering taking the repeat measurements two weeks apart.

The evidence for the construct validity of the two questionnaires was substantial. This was largely demonstrated when comparing questionnaire scores at one point in time, as well as when comparing the change in score over time with the SF-36, a generic health-related quality of life questionnaire. As expected, the study questionnaires had moderate to high correlation with the SF-36 for total score and for those domains that measure the same construct. Similarly, a previous study (26) showed that the scores on the symptoms, activities, impacts and total of the SGRQ were improved after a treatment known to be effective, but only the physical functioning, role-functioning/physical and vitality scores on the SF-36 were significantly improved. This suggests that disease-specific instruments reflect changes in patients' health more accurately following treatment. Our results also compared favourably with those of a previous study comparing the original English CRQ with the SF-36 (27).
The moderate to high correlation between the disease specific questionnaires and the SF-36 contrasts with the lower correlation observed between the two questionnaires and physiological or clinical measures such as $\mathrm{FEV}_{1}, 6 \mathrm{MWT}$ and related activity dyspnea. It is well established that in patients with COPD, the relationship between their physiological impairments and their health status measurements is generally weak $(28,29)$. However, the correlation was generally lower with the French-Canadian questionnaires than reported in previous studies with the original English CRQ $(7,30)$ and SGRQ $(8,31)$. This rather poor correlation of the French-Canadian translated questionnaires and $\mathrm{FEV}_{1}$ may be explained by the manner in which patients were selected and the type of intervention under study. Participants in our study were part of a relatively homogenous group of patients that were severely impaired by their disease. By selecting an intervention, such as pulmonary rehabilitation, it is well-known that health-related quality of life will improve despite no change in a patient's pulmonary function tests (32). We cannot assume that improvement in subjective health will accompany a measured improvement in airway function. In a complex disease such as COPD, a quality of life questionnaire is used with the expectation that it can measure 
TABLE 4

Validity of the French-Canadian translated version of the Chronic Respiratory Questionnaire (CRQ) and the St George's Respiratory Questionnaire (SGRQ): Pearson's correlation coefficients between the study questionnaire score changes at baseline and at the end of the study and other outcome measures

\begin{tabular}{|c|c|c|c|c|c|c|c|c|c|}
\hline \multirow[b]{2}{*}{ Tests } & \multicolumn{5}{|c|}{ CRQ (n=65) } & \multicolumn{4}{|c|}{ SGRQ (n=65) } \\
\hline & Total & Dyspnea & Fatigue & Emotion & Mastery & Total & Symptoms & Activity & Impact \\
\hline$\%$ predicted $\mathrm{FEV}_{1}$ & -0.04 & 0.19 & 0.11 & 0.04 & -0.06 & 0.16 & 0.20 & 0.22 & 0.04 \\
\hline Six-minute walking test & -0.10 & 0.05 & -0.25 & -0.10 & 0.04 & -0.18 & -0.03 & $-0.30^{*}$ & -0.09 \\
\hline Dyspnea after exertion & -0.02 & 0.04 & -0.03 & -0.06 & 0.01 & -0.03 & 0.04 & -0.23 & 0.05 \\
\hline $\mathrm{O}_{2}$ cost diagram & 0.12 & 0.23 & -0.12 & -0.05 & 0.03 & $0.34^{*}$ & 0.09 & -0.28 & 0.29 \\
\hline \multicolumn{10}{|l|}{ SF-36 } \\
\hline Total score & $0.44^{*}$ & 0.24 & $0.48^{*}$ & $0.42^{*}$ & 0.11 & $-0.31^{*}$ & -0.15 & -0.28 & -0.20 \\
\hline Physical functioning & 0.22 & $0.30 *$ & 0.26 & 0.20 & -0.14 & $-0.41^{*}$ & -0.25 & -0.28 & $-0.32^{*}$ \\
\hline Role functioning/emotion & 0.23 & 0.15 & $0.30^{*}$ & 0.11 & 0.14 & -0.15 & -0.13 & 0.03 & -0.13 \\
\hline Role functioning/physical & 0.26 & 0.21 & $0.32^{*}$ & 0.19 & 0.05 & $-0.46^{*}$ & -0.17 & $-0.48^{*}$ & $-0.31^{*}$ \\
\hline General health perception & -0.05 & 0.01 & 0.10 & -0.07 & -0.17 & -0.01 & -0.10 & 0.09 & -0.04 \\
\hline
\end{tabular}

*Statistically significant $(P<0.05)$. FEV 1 Forced expiratory volume in $1 \mathrm{~s}$; SF-36 36-item short form health survey

constructs different than those reflected by physiological parameters $\left(\mathrm{FEV}_{1}\right)$, exercise capacity $(6 \mathrm{MWT})$ or dyspnea with activity (OCD and dyspnea after exertion).

In our study, in applying the questionnaires, we made the assumption that they all refer to the same period of time. Except for the symptoms dimension of the SGRQ, the questionnaires all look at a recent period of time. The CRQ looks at the past two weeks and the SGRQ looks at the past year for respiratory symptoms and "these days" for activity and impact scores. The SF-36 looks at the present time. With respect to the intervention settings, the questionnaires assessed changes over a period of four weeks for patients under treatment for an exacerbation and eight to 12 weeks for patients taking part in a pulmonary rehabilitation program. This could explain why the symptoms dimension of the SGRQ which refers to "the last year" showed little or no correlation with other outcomes.

Finally, our study showed that the French-Canadian versions of the CRQ and SGRQ were responsive to changes. In addition to showing improvement with a given intervention known for its effectiveness, the questionnaires also demonstrated that the improvement was larger relative to the variability in patients with stable disease. The CRQ, the SGRQ subscale (except for the symptoms dimension) and total scores increased from the baseline variations of patients with stable disease by two- to threefold in patients when improvement was expected. Again, it is important to note that the symptoms dimension of the SGRQ was not developed to evaluate change or respond to an intervention within a short period of time because the questions refer to "the last year".

\section{CONCLUSION}

The present study confirms that the French-Canadian versions of the CRQ and the SGRQ performed well with respect to their psychometric properties. We also demonstrated that health status instruments can provide additional information to supplement the other clinical and physiological measures used in clinical research. The results of our study, in terms of reliability, validity and responsiveness, did not clearly favour one instrument over another, as previously shown in other studies $(28,33,34)$. As expected, the symptoms dimension domain of
TABLE 5

Responsiveness of French-Canadian translated version of the Chronic Respiratory Questionnaire (CRQ) and the St George's Respiratory Questionnaire (SGRQ)

\begin{tabular}{|c|c|c|c|}
\hline & $\begin{array}{l}\text { Stable disease } \\
\text { group* } \\
(n=27)\end{array}$ & $\begin{array}{c}\text { Disease } \\
\text { improvement } \\
\begin{array}{c}\text { group } \\
(n=65)\end{array}\end{array}$ & $\begin{array}{l}\text { core change ratio } \\
\text { (improvement } \\
\text { group: } \\
\text { stable group) }\end{array}$ \\
\hline \multicolumn{4}{|c|}{$\mathrm{CRQ}$ (mean [95\% Cl]) } \\
\hline Total & $7.0(4.7$ to 9.4$)$ & 14.7 (11.1 to 18.3$)$ & 2.1 \\
\hline Dyspnea & $2.2(0.9$ to 3.5$)$ & $4.2(3.0$ to 5.0$)$ & 1.9 \\
\hline Fatique & 2.1 (1.3 to 3.0$)$ & 4.1 (2.9 to 5.3$)$ & 2.0 \\
\hline Emotion & $1.5(0.4$ to 2.6$)$ & $3.6(2.2$ to 5.1$)$ & 2.4 \\
\hline Mastery & $0.8(0$ to 1.6$)$ & $2.6(1.6$ to 3.6$)$ & 3.3 \\
\hline \multicolumn{4}{|c|}{ SGRQ (mean [95\% CI]) } \\
\hline Total & $-2.4(-0.3$ to -4.6$)$ & $-7.2(-4.2$ to -10.2$)$ & 3.0 \\
\hline Symptoms & $-4.4(-0.2$ to -9.1$)$ & $-4.0(-1.0$ to -9.1$)$ & 0.9 \\
\hline Activity & $-1.2(-1.8$ to -4.1$)$ & $-6.5(-3.0$ to -10.1$)$ & 5.4 \\
\hline Impact & $-2.6(0$ to -5.2$)$ & $-8.0(-3.9$ to -12.2$)$ & 3.1 \\
\hline
\end{tabular}

*Mean extent to which score changed. CRQ scores range from 5 to 35 for dyspnea, 4 to 28 for fatigue, 7 to 49 for emotional function, 4 to 28 for mastery and 20 to 140 for total score. SGRQ scores range from 0 to 100

the SGRQ cannot be used to assess acute changes from a given therapy. We believe that the French-Canadian versions of the CRQ and the SGRQ are suitable for their intended purpose, ie, to detect change in the health status of patients with COPD when assessing the benefits of a treatment.

FUNDING: The authors would like to thank the Fonds de la Recherche en Santé du Québec (FRSQ) (Research Scholarships to JB and FM) and the Association Pulmonaire du Québec (APQ) for funding this study.

ACKNOWLEDGEMENTS: The authors are indebted to all the patients with chronic obstructive pulmonary disease who participated in this study. The authors thank the following persons who coordinated the study within their respective centre: Marie Josée Breton and Marthe Bélanger from Laval Hospital; Monica Krusky from St-Sacrement Hospital; and Grace Geraldi and Livia Fargolia from the Montreal Chest Institute. The authors also thank Ravinder Singh for assisting in data analysis and Louise Auclair from the Respiratory Epidemiology and Clinical Research Unit for secretarial assistance. 


\section{REFERENCES}

1. Ferrer M, Alonso J, Morra J, et al. Chronic obstructive pulmonary disease stages and health-related quality of life. The Quality of Life of Chronic Obstructive Pulmonary Disease Study Group. Ann Intern Med 1997;127:1072-9.

2. Seemungal TA, Donaldson GC, Paul EA, Bestall JC, Jeffries DJ, Wedzicha JA. Effect of exacerbation on quality of life in patients with chronic obstructive pulmonary disease. Am J Respir Crit Care Med 1998;157:1418-22.

3. McGavin CR, Artvinli M, Naoe H, McHardy GJ. Dyspnoea, disability, and distance walked: Comparison of estimates of exercise performance in respiratory disease. Br Med J 1978;2:241-3.

4. Reardon J, Patel K, ZuWallack RL. Improvement in quality of life is unrelated to improvement in exercise endurance after out-patient pulmonary rehabilitation. J Cardiopulm Rehabil 1993;13:51-4

5. Mahler DA, Wells CK. Evaluation of clinical methods for rating dyspnea. Chest 1988;93:580-6.

6. Jones PW. Application of quality-of-life measures in chronic obstructive pulmonary disease. Clin Pulm Med 1997;4:131-4.

7. Guyatt GH, Berman LB, Townsend M, Pugsley SO, Chambers LW. A measure of quality of life for clinical trials in chronic lung disease. Thorax 1987;42:773-8

8. Jones PW, Quirk FH, Baveystock CM, Littlejohns P. A self-complete measure of health status for chronic airflow limitation.

The St. George's Respiratory Questionnaire. Am Rev Respir Dis 1992;145:1321-7.

9. Guillemin F, Bombardier C, Beaton D. Cross-cultural adaptation of health-related quality of life measures: Literature review and proposed guidelines. J Clin Epidemiol 1993;46:1417-32.

10. American Thoracic Society. Standards for the diagnosis and care of patients with chronic obstructive pulmonary disease. Am J Respir Crit Care Med 1995;152:S77-121.

11. Knudson RJ, Lebowitz MD, Holberg CJ, Burrows B. Changes in the normal maximal expiratory flow-volume curve with growth and aging. Am Rev Respir Dis 1983;127:725-34.

12. Guyatt GH, Townsend M, Berman LB, Pugsley SO. Quality of life in patients with chronic airflow limitation. Br J Dis Chest 1987;81:45-54.

13. Lacasse Y, Wong E, Guyatt GH, Goldstein RS. Health-status measurement instruments in chronic obstructive pulmonary disease. Can Respir J 1997;4:152-64.

14. Ware JE Jr, Sherbourne CD. The MOS 36-item short form health survey (SF-36). I. Conceptual framework and item selection. Med Care 1992;30:473-83.

15. Perneger TV, Leplege A, Etter JF, Rougemont A. Validation of a French-language version of the MOS 36-Item Short Form Health Survey (SF-36) in young healthy adults. J Clin Epidemiol 1995;48:1051-60

16. McHorney CA, Ware JE Jr, Raczek AE. The MOS 36-Item Short-Form Health Survey (SF-36): II. Psychometric and clinical tests of validity in measuring physical and mental health constructs. Med Care 1993;31:247-63.

17. American Thoracic Society. Standardization of spirometry: 1987 update. Statement of the American Thoracic Society. Am Rev Respir Dis 1987;136:1285-98.
18. Butland RJA, Pang J, Gross ER, Woodcock AA, Geddes DM. Two-, six-, and twelve-minute walking tests in respiratory disease. Br Med J (Clin Res Ed) 1982;284:1607-8.

19. Muza SR, Silverman MT, Gilmore GC, Hellerstein HK, Kelsen SG. Comparison of scales used to quantitate the sense of effort to breathe in patients with chronic obstructive pulmonary disease. Am Rev Respir Dis 1990;141:909-13.

20. Gift AG. Validation of a vertical visual analogue scale as a measure of clinical dyspnea. Rehabil Nurs 1989;14:323-25.

21. Mahler DA, Rosiello RA, Harver A, Lentine T, McGovern JF, Daubenspeck JA. Comparison of clinical dyspnea ratings and psychophysical measurements of respiratory sensation in obstructive airway disease. Am Rev Respir Dis 1987;135:1229-33.

22. O'Donnell DE, McGuire M, Samis L, Webb KA. The impact of exercise reconditioning on breathlessness in severe chronic airflow limitation. Am J Respir Crit Care Med 1995;152:2005-13.

23. Guyatt GH, Bombardier C, Tugwell PX. Measuring disease-specific quality of life in clinical trials. Can Med Assoc J 1986;134:889-95.

24. Wijkstra PJ, TenVergert EM, Van Altena R, et al. Reliability and validity of the chronic respiratory questionnaire (CRQ). Thorax 1994;49:465-7.

25. Jones PW, Quirk FH, Baveystock CM. The St George's Respiratory Questionnaire. Respir Med 1991;85(Suppl B):25-31,33-7.

26. Jones PW, Bosh TK. Quality of life changes in COPD patients treated with salmeterol. Am J Respir Crit Care Med 1997;155:1283-9.

27. Martin LL. Validity and reliability of a quality-of-life instrument. The chronic respiratory disease questionnaire. Clin Nurs Res 1994;3:146-56.

28. Hajiro T, Nishimura K, Tsukino M, Ikeda A, Koyama H, Izumi T. Comparison of discriminative properties among disease-specific questionnaires for measuring health-related quality of life in patients with chronic obstructive pulmonary disease. Am J Resp Crit Care Med 1998;157:785-90.

29. Curtis JR, Deyo RA, Hudson LD. Pulmonary rehabilitation in chronic respiratory insufficiency. 7 . Health-related quality of life among patients with chronic obstructive pulmonary disease. Thorax 1994;49:162-70.

30. Guyatt GH, Nogradi S, Halcrow S, Singer J, Sullivan MJ, Fallen EL. Development and testing of a new measure of health status for clinical trials in heart failure. J Gen Intern Med 1989;4:101-7.

31. Ketelaars CA, Schlosser MA, Mostert R, Huyer Abu-Saad H, Halfens RJ, Wouters EF. Determinants of health-related quality of life in patients with chronic obstructive pulmonary disease. Thorax 1996;51:39-43.

32. Lacasse Y, Wong E, Guyatt GH, King D, Cook DJ, Goldstein RS. Meta-analysis of respiratory rehabilitation in chronic obstructive pulmonary disease. Lancet 1996;348:1115-9.

33. Harper R, Brazier JE, Waterhouse JC, Walters SJ, Jones NM, Howard P. Comparison of outcome measures for patients with chronic obstructive pulmonary disease. Thorax 1997;52:879-87.

34. Rutten van Mölken M, Roos B, van Noord JA. An empirical comparison of the St George's Respiratory Questionnaire (SGRQ) and the Chronic Respiratory Disease Questionnaire (CRQ) in clinical trial setting. Thorax 1999;54:995-1003. 


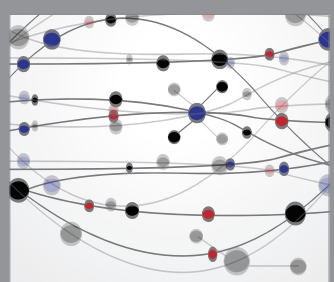

The Scientific World Journal
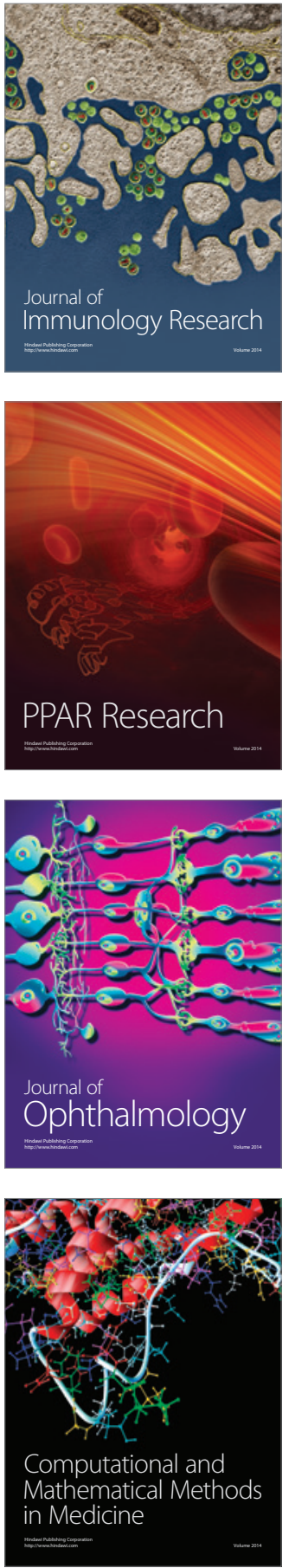

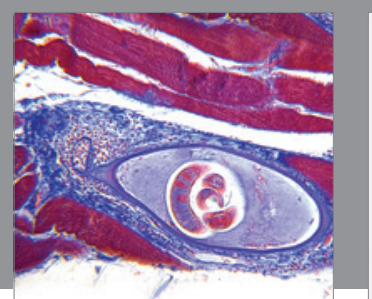

Gastroenterology Research and Practice

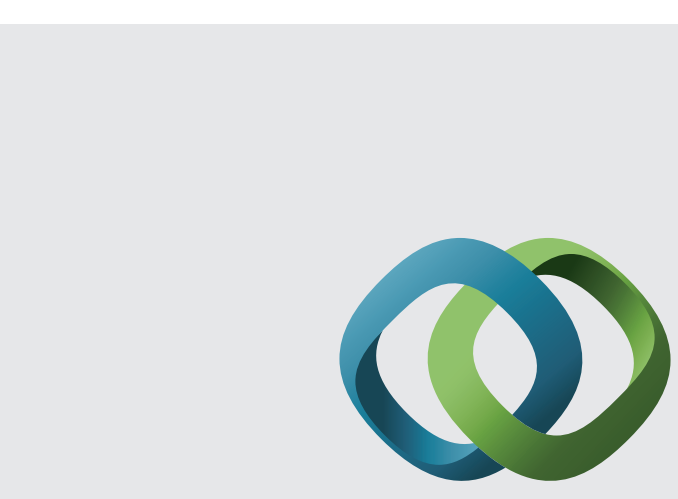

\section{Hindawi}

Submit your manuscripts at

http://www.hindawi.com
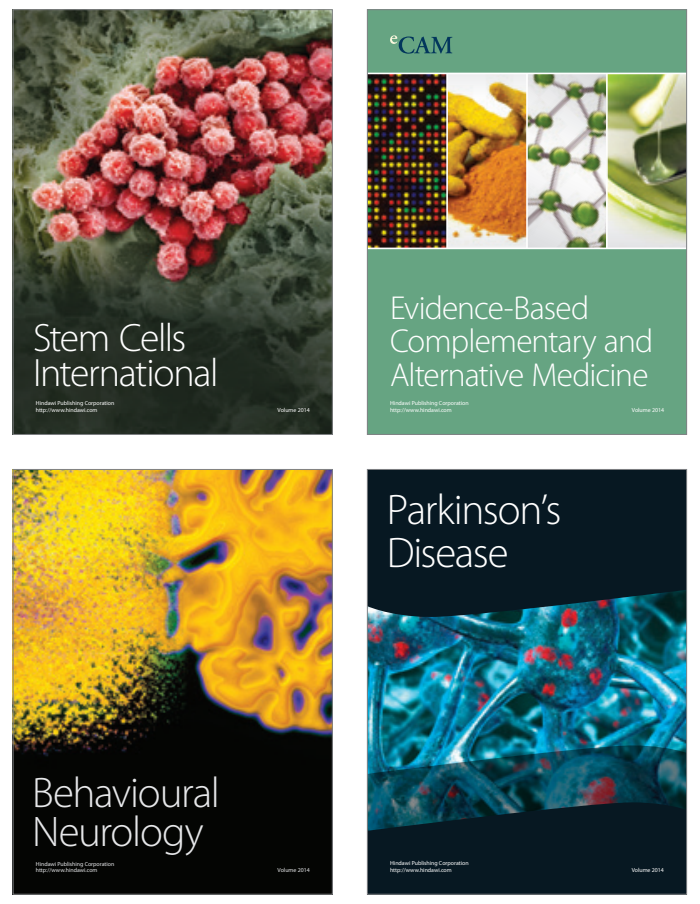
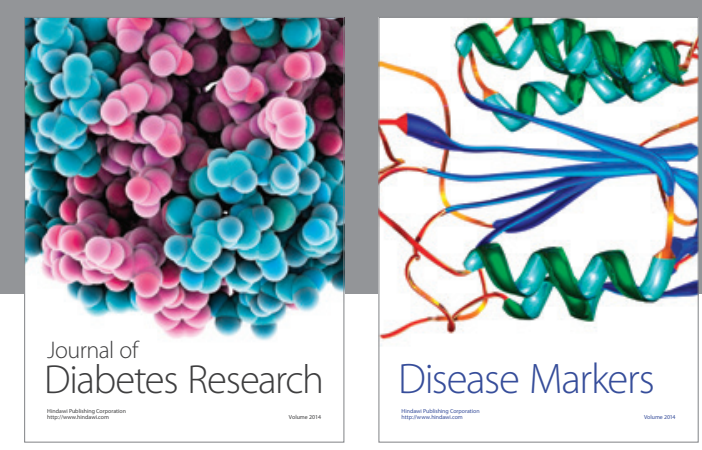

Disease Markers
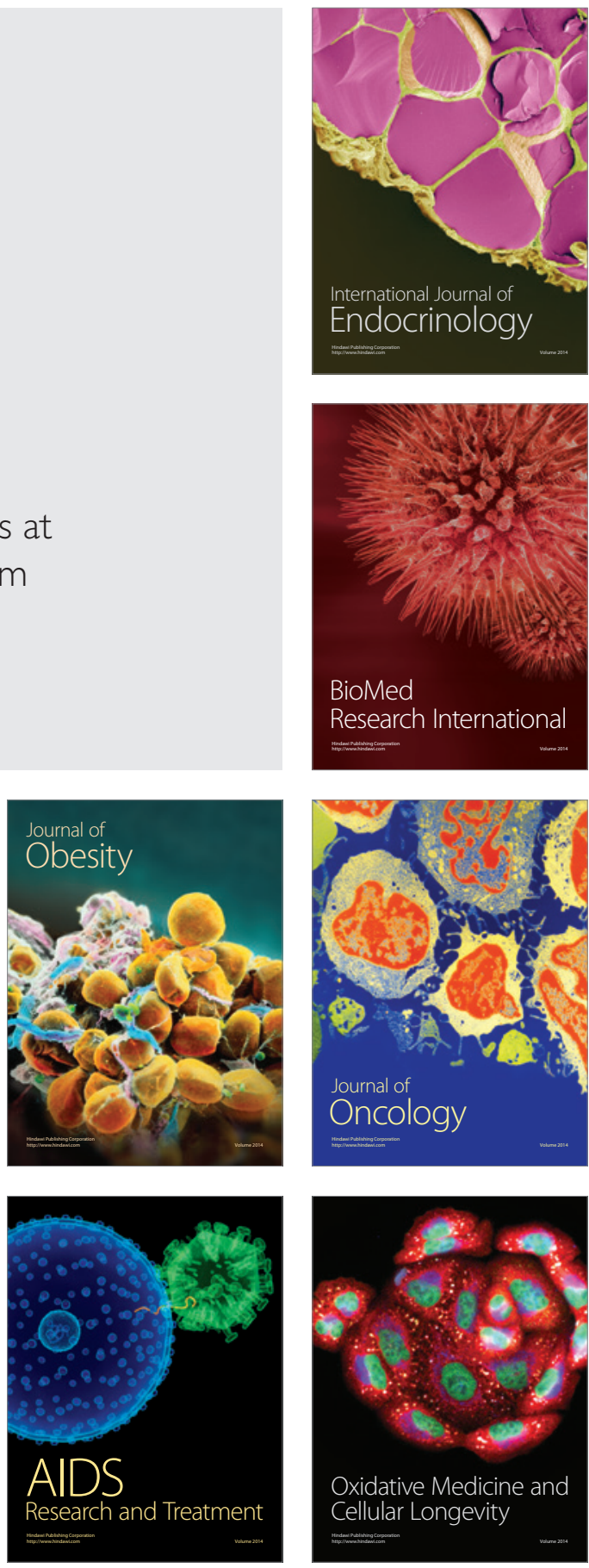